\title{
6
}

\section{Color-Coded Course Design: Educating and Engaging Faculty to Educate and Engage Students}

\section{Marlene M. Preston}

Virginia Polytechnic Institure and State University

In a weeklong seminar, "Course Design to Foster Student Engagement and Learning, "faculty created course charts to reflect their various plans for an upcoming semester. With colorful Post-it Notes, they applied theoretical principles of course design. Participating in the kind of active environment they might want to create for students, faculty constructed their charts, rearranged the components to achieve balance across the semester, and discussed the plans with their colleagues. This case study includes the rationale for and description of "Color-Coded Course Design," a process that allows faculty to recognize and experience the power of an active classroom.

M any faculty have a tried-and-true approach to course design. They may use a straightforward, teacher-centered process of receiving a teaching assignment, choosing a book, creating assignments for the semester, and sprinkling in some tests for "good" measure! They move on to develop their lecture materials, pull together a syllabus, and march off to the first day of the semester. While curriculum designers may cringe, many faculty are comfortable with this approach, and they may be looking only for some superficial tweaking to spark their courses. In an attempt to find a tool that would create fundamental change in their design process, I developed a color-coded design process that challenges faculty to consider a wide range of interdependent course components. The following case study examines the goals, strategies, and outcomes for a faculty development activity designed to engage faculty in the same way that they should be engaging their students in the classroom. 


\section{The Goals of The Design Workshop}

The context for this case study is the annual week-long workshop offered by the University Writing Program under the auspices of Virginia Tech's Center for Excellence in Undergraduate Teaching. This faculty development activity has been in place for ten years and has recently evolved from a set of activities devoted primarily to supporting faculty who are implementing writing intensive courses to a more comprehensive focus on course design. The logic of this change is that faculty members need to understand how a more holistic design framework could enhance student communication skills, promote student engagement, and foster intellectual development. The revised workshop would feature integration of student writing and speaking as part of the course plan-informal writing and speaking for processing new ideas, and formal writing and speaking for demonstration of mastery.

As I structured a week-long workshop, "Course Design to Foster Student Engagement and Learning," I considered many of the same components I would advocate to faculty for their consideration in course design: needs, goals, learners, content, environment, instructional strategies for delivery and processing, pacing, and assessment/demonstration of mastery.

In their applications for the workshop, faculty described their areas of interest. Most expressed a need to heighten student involvement in their classes. Some had recognized a gap between their current practice and the kind of student engagement they had either read about or heard about. In broader terms, I identified two gaps: 1) between their current practice and contemporary learning theory, and 2) between their personal experience as students and the experience they desired for their own students. Not only were they unfamiliar with the learning theory, but they also had not experienced active classrooms when they themselves were undergraduates. Especially at a research institution, some felt little incentive to risk stepping out of familiar teacher-centered design patterns.

As experts in the theory of their own disciplines, faculty would not necessarily be interested in studying the complexities of learning theory. My training in curriculum and instruction was important to them, and they would trust me to pass along the highlights; most were more interested in application. To capture their interest and meet that need, I had to develop a plan that would embed the theory and would produce concrete strategies for future course design.

To heighten interest in effective course design and student engagement, a learning environment was designed to make faculty feel safe enough to take risks, to experiment with their course designs, and to participate fully in the 
activities designed to promote learning and application of new strategies. The promotion of the workshop included the following information:

"We'll start with your course materials and consider the following as we meet each day:

1) Ways to organize those materials for maximum student attention and benefit

2) Approaches to classroom implementation that include student writing and speaking

3) Choices for efficient and meaningful assessment

By the end of our week together, you'll have a solid framework for your fall class."

The language was chosen to frame the workshop in a way that seemed familiar to faculty - promising to build on their existing materials and avoiding any mention of group activities or playfulness! Faculty would have to attend the workshop and build some trust before being asked to bond in base groups, share concerns and even mistakes, and work within the kind of climate they might eventually want to see in their classrooms-safe, but appropriately challenging.

\section{Color-Coded Course Design Tool}

The Color-Coded Course Design Tool became a vehicle to examine course planning at deep levels. The use of course-design charts with poster-sized graph paper and Post-it Notes created a colorful work environment, allowed faculty to rearrange course components, and fostered problem solving with peers. This approach to design extended what is offered in design texts and templates by providing a hands-on, collaborative environment that removed much of the abstractness inherent in design theory. Additionally, it was rooted in a faculty member's current design approach, rather than beginning with the curriculum designer's gap analysis based on the evaluation of multiple facets.

The Color-Coded Course Design Tool evolved from a simple chart I had developed earlier to discuss pacing for the semester. I had created this chart as a graphic to support my discussions with faculty about the differences between semesters with a mid-semester break and those with a late semester break. My collcague, Margaret Hable, a consultant with our Center for Excellence in Undergraduate Teaching, suggested that we transfer my chart to poster-board for each participant with exhibits of these boards around the room. After considerations of portability and costs, I searched for chart-sized 
graph paper that we could easily hang on the walls. With Post-it-style graph paper secured, an undergraduate student set to work creating a chart for each participant to reflect either fall or spring semester. She marked the dates of the semester along the horizontal axis at the top, including breaks and exams (see Table 6.1). She did not fill in the topics that faculty would eventually consider in the left column. Faculty added those topics as we moved from one concept to the next during the workshop.

TABI.E 6.1

Partial Course Design Template for Fall Semester

\begin{tabular}{l|l|l|l|l|l}
\hline Course Components & $\begin{array}{c}8 / 26 \\
\text { Week 1 }\end{array}$ & $\begin{array}{c}9 / 2 \\
\text { Week 2 }\end{array}$ & $\begin{array}{c}9 / 9 \\
\text { Week 3 }\end{array}$ & $\begin{array}{c}9 / 16 \\
\text { Week 4 }\end{array}$ & 9/23, etc. \\
\hline 1) Content-pink & & & & & \\
\hline 2) Delivery-turquoise & & & & & \\
\hline 3) Assignments-blue & & & & & \\
\hline 4) Tests and quizzes-red & & & & & \\
\hline $\begin{array}{l}\text { 5) Environment and } \\
\text { motivation-green }\end{array}$ & & & & & \\
\hline $\begin{array}{l}\text { 6) Processing-yellow } \\
\text { 7) Mastery-purple }\end{array}$ & & & & & \\
\hline 8) Skills-orange & & & & & \\
\hline 9) Other? & & & & & \\
\hline
\end{tabular}

\section{DESIGN OF THE WORKSHOP}

The week's design included attention to content, collegiality, and comfort for faculty as they would be urged to shift from a teacher-centered design process to a more learner-centered design process. We planned to provide brief presentations about learning theory and assignment design, much time for faculty conversation with colleagues and attention to their own course designs, and a pleasant setting. Rather than trying to teach all the concepts related to course design, we wanted faculty to be aware of concepts, feel the power of the activities, identify useful strategies for their own courses, and find resources for 
further investigation. Any presentation about learning theory or course design principles was brief and followed by some individual or group activity.

We used a large dining room with round tables, sufficient wall space for the wall charts, and flexible work and eating space. Our caterer decided on ethnic foods from various countries-a theme for each day-and we planned reminders for faculty to think about the diversity in their classrooms as we "visited" a different country each day. Overall, we planned for an experience that would be friendly and productive.

Faculty were assigned to base groups comprised of faculty in similar disciplines. These groups were used as a starting point each day although other configurations were also made-groups of faculty teaching the same age students or teaching in the same types of classrooms (lab, large lecture, seminar). Faculty moved into these groups to gain multiple perspectives as various topics arose.

At each table, faculty found their personal materials and "table copies" of various resources. Each participant received gifts: a journal (a classic composition book with the marbled black-and-white cover) for reflection writing, a copy of John Bean's Engaging Ideas (1996), and a folder in which to collect handouts or notes. Over the course of the week, faculty were asked to do informal writing in their composition books, to read specific sections in the main text, and to review table copies of other texts. These texts included numerous books related to student writing and college teaching:

The Craft of Scientific Writing (Alley, 1996)

A WAC Casebook (Anson, 2002)

Knowing and Reasoning in College (Baxter-Magolda, 1992)

Making Their Own Way (Baxter-Magolda, 2001)

New Paradigms for College Teaching (Campbell \& Smith, 1997)

Teaching Within the Rhytloms of the Semester (Duffy \& Jones, 1995)

The Course Syllabus (Grunert, 1997)

The Transition to College Writing (Hjortshoj, 2001)

Active Learning (Johnson, Johnson, \& Smith, 1998)

How Writing Shapes Thinking (Langer \& Applebee, 1987)

Writing to Learn (Sorcinelli \& Elbow, 1997) 
Grading Students' Classroom Writing (Speck, 2000)

Helping Students Write Well (Walvoord, 1986)

\section{Thinking and Writing in College (Walvoord \& McCarthy, 1990)}

The texts not only supported the week's work, but also gave faculty a glimpse of the resources available for their use in our teaching center and writing program. Faculty reviews were written on index cards, discussed in base groups, and compiled by the end of the week for everyone's use.

\section{Beginning With the Known: Teacher-Centered Design Decisions}

To begin work with the Color-Coded Course Design Tool, each participant received a poster-sized chart already marked with the weeks of the semester and a multicolored collection of Post-it Notes. Faculty labeled the charts with their names and courses and then proceeded to label and complete the first four rows of the chart, reflecting an existing plan for the semester. Thus, the activity opened in a faculty comfort zone-a teacher-centered starting point-but one that affirmed prior knowledge and acknowledged faculty as experts, people who would be contributing their expertise to the workshop along with the presenters. This also served as somewhat of a diagnostic activity because it revealed any determination to cover material even if the time was inadequate for student activity and processing. Attention to prior knowledge and expectations would also be the first consideration we would want faculty to make concerning their own students.

Row 1: Course content. To start with material the faculty knew well, our first topic of discussion was content. Faculty were asked to bring six to eight main topics/concepts/ideas to the first day's meeting. They were also asked to review the course description (which some faculty admitted they had never read before), and to bring any course goals they had established or prior syllabi. On one color of Post-it, they listed one topic on each note and then arranged the topics on the chart as they might be taught across the semester. We acknowledged their expertise in this area and didn't presume to suggest any rearrangement of topics, nor did we limit the number of topics, even though some faculty couldn't reduce the number to eight.

Row 2: Delivery of information. Again, as a point of familiarity, faculty listed their delivery strategies on a second color of Post-its, and positioned these notes across the row. Many notes listed "lecture" in every block across the row. A few included notes about individual student or group presentations designed to teach course content to the class. 
Row 3: Assignments. Reflecting an existing course or a typical plan, faculty used a third color note for any reading assignments, graded homework, and writing or spcaking assignments. They effortlessly sprinkled these assignments across the row with some kind of formula, such as homework every week, writing every three weeks, and maybe an oral presentation at the end of the semester.

Row 4: Tests and quizzes. Still building on their typical plans, faculty then used a fourth color Post-it to depict a pattern of quizzes and tests to coincide with the topics and assignments.

When they had finished rows one through four of their charts, faculty posted their charts around the room and seemed confident that they had already mastered the art of course design. Some probably figured the course planning had been accomplished, and we should move on to writing a syllabus.

\section{Learner-Centered Instructional Considerations}

However, we then moved on to strategies that enhance motivation, engagement, and long-term learning. Beginning at this point in the workshop, faculty were encouraged to reexamine their assumptions about course design.

Row 5: Environment and motivation. We began to discuss various aspects of morivation and classroom/campus climate, including prior knowledge, individual differences, student goals, predictable distractions, and student energy. Focusing on the need for individuals to feel connected and safe, we discussed ways to build community, to create an atmosphere in which students are not afraid to experiment and take risks. Based on the work of Duffy and Jones (1995), we talked with faculty about the predictable cycles of the semester that should be considered as part of course planning:

- Early Semester: Set context. Assess skills, expectations, and prior knowledge. Build community.

- Mid-Semester: Maintain interest. Balance the routine and the surprise. Build skills and content mastery. Alternate presenters of course content. Wecks two through 12 most useful for presentation, processing, application of new material.

- Late Semester: Wind down. Summarize. Articulate connections of course material to other courses. Encourage student reflection.

We assigned a fifth color for these considerations, and faculty added notes to their course charts. They were encouraged to plan time during the first weeks 
of class to capitalize on student interest and energy, to identify prior knowledge, and to help students set goals. They were reminded that even in our workshop, we had immediately established base groups to help participants connect with colleagues. We considered the placement of semester breaks, weather, mid-week football games, seniors who are interviewing, and freshmen who are homesick. While we may not appreciate the fact that a football game or fraternity rush distracts our students, we suggested that faculty at least consider their impact on the learning environment. Faculty were also urged to plan time for reflection at the end of the semester.

As faculty acknowledged the "dead" times during the semester and the futility of addressing content when students are exhausted, they broke into groups based on the level of students in their classes. Without regard for discipline, they shared observations and solutions related to their freshmen, sophomores, juniors, or seniors. They discussed ways to engage their students and protect themselves during times when students were not likely to be responsive.

When they approached their charts with the fifth row of notes, they were forced to rearrange some earlier notes. If the first week of the class would be used for community building and consideration of students' prior knowledge, that first topic in the Row 1 (content) had to move to week two. If the semester had only a late break, such as a fall break at Thanksgiving, faculty had to reconsider the amount of content they could present to fatigued students during the week before Thanksgiving and in the week between Thanksgiving and exams.

While this row became somewhat of a catch-all, these discussions seemed to create the most fundamental change in the ways faculty thought about student learning and course pacing. By this point in the workshop, faculty were beginning to experience the power of their work in teams and the advantages of consulting with one another.

Row 6: Processing. How do students learn? How do they move from the lecture to the exam to the long-term acquisition of information? Faculty discussed their own strategies for learning and ways to help students understand new concepts and make meaning for themselves. We also discussed students' ways of knowing, based on the work of Marcia Baxter-Magolda (1992 \& 2001) and the developmental levels at which students are ready to undertake various levels of complexity and uncertainty. Faculty were somewhat familiar with the litcrature on learning styles, and this discussion of processing helped them consider ways to provide multiple types of experiences of students. We began to consider the ways in which faculty can support students as they process new material, connect it to concepts they already know, recognize its value, and consider its useful application. 
Faculty reviewed the homework assignments (Row 3), and considered alternatives to straight-recall questions about the content of a chapter. We challenged faculty to incorporate opportunities for cooperative learning so that students could learn the value of interdependence and enriched problem solving.

We considered the literature related to informal writing and speaking, and asked faculty to build in opportunities for reflection writing, journals, impromptu speeches, group discussion-any activity that would allow students to communicate their understandings and questions to others. Bean's (1996) text was especially useful in the consideration of groups and informal writing. On a sixth color of Post-it Notes, faculty planned these activities across the semester.

Row 7: Demonstrating mastery. Once students have processed new ideas, of course, they should have the opportunity to demonstrate their mastery of those ideas. Faculty were asked to review assignments in Row 3 and the tests and quizzes listed in Row 4 and to consider alternate ways for students to demonstrate mastery. For example, a group presentation could replace a test and a week of lecture on a topic. At this point in the workshop, we discussed assignment development and formal writing and speaking. As coordinator of the University Writing Program, I had the sense that faculty had previously heard enough from me about the power of writing in their courses, so we invited a guest presenter to discuss the development, implementation, and assessment of formal writing assignments. Faculty found the sections in Engaging Ideas (Bean, 1996) to be particularly helpful regarding feedback on student papers and managing the paper load. On a seventh color of Post-it Notes, faculty added notes about formal assignments, including attention to the timeframe for outlines and drafts.

In terms of more traditional tests, we reminded faculty about the need for valid assessments that matched the course goals. We provided other campus resources to address specific assessment questions.

We also reminded faculty to plan time for thorough evaluation of student work so that students were not asked to turn in subsequent papers before previous papers or essay exams had been graded. Again, faculty adjusted Post-jt Notes on various rows of their course charts to allow for better feedback to students. (Later a faculty member noted that she needed to line up the course charts for each of her courses so that she didn't set herself up to grade major assignments from different courses at the same time.)

Row 8: Skill-building. Once the course components seemed set, faculty were asked to consider student skills. Did students have the skills to write a research paper, present a group discussion, use Blackboard or PowerPoint? We 
reminded faculty to consider student preparation for these assignments. Had students received formal instruction on the use of the library or the processes for group problem solving? Faculty needed to plan time to ascertain student skills and/or teach some of these processes before they could expect students to perform well.

As faculty added the eighth color of Post-It Note for lessons in information literacy, writing process, or oral presentations, they found themselves shifting other Post-its to create time for these "extra" lessons.

\section{Reconsideration of Course Components}

As faculty completed the rows of their course charts, the room was festooned with colorful displays of their work. They were invited to explore the designs colleagues were working on, and there was much discussion as faculty problem solved with partners about the fit of certain course components. Over the course of the week, we had invited guest faculty to join us for lunch and to discuss their successes with course design and student writing. Conversations with other participants and with faculty "experts" who visited the workshop had sparked some new ideas about content and strategies.

Now that they had a concrete picture of the semester, faculty struggled to fit everything in, shifting Post-it Notes on various rows. Some reviewed their content delivery plans and sought to reduce the lecture time. Some asked for more information about case studies as they considered incorporating group work on cases. Others were planning to use student oral or written presentations to deliver content.

Other participants added further rows for considerations unique to their own courses. Some created a row of color to show time necessary for feedback and processing of student work so that they could better balance these demands with other components. Others created a row for group processes and products so that they could see the timeline for the development of a group project, including instruction about groups and group meeting time in class so that faculty could monitor progress.

\section{Syllabus Design}

Although some faculty had wanted to move to syllabus design early in the week, we cautioned them not to lock into a syllabus until they felt sure they had considered all of the facets of their courses. Finally, we reviewed syllabi components, shared various models, and attempted to see what students see when they read a syllabus. On each table was a copy of The Course Syllabus: $A$ Learning-Centered Approach (Grunert, 1997), which we had referred to during 
the week and which most faculty had at least perused by the end of the week. The creation of a syllabus, however, would be completed once faculty left the workshop.

\section{Faculty Response}

Faculty offered positive feedback about the workshop, but some of them had to be won over as the workshop progressed. Some faculty seemed to hold onto the notion that learning can't be fun. They seemed suspicious of activities that created movement in the room, group conversation, or even laughter. Clearly they were used to and most comfortable with a lecture format. However, most began to come around to the warmth of the environment, greeting base groups as they would old friends, offering to mentor others, and even dressing for the country represented by the lunch of the day! Many hallmarks of learning communities emerged-shared work in a shared space, interdependence, inside jokes, and course design charts as artifacts. Faculty also began bringing their own favorite resources to share with groups, such as web sites for case studies and lists of grammar reminders.

Participants returned again and again to the rows on their charts, rearranging and often deleting as they examined the match of the content with course goals and student needs for long-term learning. They came to trust their colleagues and solicit their advice when they were struggling with compering course components.

Of course, there was one exception who repeatedly claimed that the concepts did not apply in his course. His body language and side comments to those at his table nearly undermined the work of that group. He even finished the week with a harangue to the presenters and fellow participants about the "touchy-feely" nature of the activities. Of course, he had declined to participate in most of them, so certainly he experienced no transformation. Amazingly, once the workshop was over, he contacted another participant (in a different discipline from his own) and asked for assistance with his course. The workshop setting was apparently too public for him, but he did attend each day and then finally created his own support system to work on course design and instructional strategies.

As the workshop drew to a close, faculty were already considering applications for the design tool. One person asked about using the Color-Coded Course Design Tool with graduate students to give them a "picture" of the semester; others were considering office walls upon which to hang the charts while they continued to experiment with the arrangenent of the l'ost-it Notes. Others were squirreling away pockets full of Post-it Notes so that they 
could use them later when they worked on their course charts. Many faculty borrowed books from our center's library so that they could further explore some of the concepts we had introduced.

At the end of the workshop, faculty feedback was positive. One faculty member asked permission to do a mini-workshop to share the strategy with her colleagues in career services. Participants immediately used the tool after the workshop. One found application in her study-abroad course in Australia:

Here I am "down under" with the students studying information technology, and we are having a ball. I used the ideas from the workshop to design the writing assignment we are using - the workshop was just wonderful. I will be using all the ideas as I continue work on the new course I am teaching this fall, but I did want you to know that the workshop had an immediate impact on me for the Study Abroad.

Other comments included the following:

My charts are on the wall of my office and I'm referring to them religiously. I feel completely inspired for the fall; this was the best thing that ever happened to me as a teacher.

My colleagues are so impressed by the accounts I give and the stunning Post-it plan that they've asked me to summarize the workshop for them at a faculty development meeting in a couple of weeks. I benefited from reviewing the main ideas again, and several of the other teachers expressed interest in attending the next workshop!

I believe it shows that you can teach an old dog new tricks, as I learned several things I intend to try out in the fall.

My class prep is going wonderfully. Yours is the best workshop I have ever been to ... in terms of applying knowledge to real-life stuff.

I am continuing to work on my Post-it plan. It has been extremely helpful for me. I am a visual learner, so this was a great way for me to see how it will come together for the semester.

After the May workshop, faculty were invited to a reunion during fall semester so that they could share successes and problems-especially any new 
complexities that arose because of a course-design decision. Although the reunion meeting was held in October, one participant came in his beach T-shirt and sandals, wanting to recall the warm days of May when we worked together on course design. (Yes, he's the one who dressed in ethnic costume for the meals, too.) Faculty discussed their use of the plan, their need for more wall space in their offices, and the "mistakes." For example, one faculty member scheduled a test the morning after a mid-week football game. Although he admitted that he wouldn't have considered this previously, he ended up moving the test because he realized that he could have avoided the problem had he checked that calendar to begin with. Another had planned a final week of the semester for reflection and review so that students could put her course into perspective.

\section{Application}

The Color-Coded Course Design Tool could work for any course across a broad range of disciplines. Titles of rows, colors of Post-its, activities, and resource materials might easily be shifted to match the goals of various audiences.

Whilc it was used in this workshop with experienced faculty, it could also be useful with beginning teachers or graduate students, those who have not yet developed a "picture" of the entire semester based on their own experience. One faculty member suggested that she might ask her graduate students to map out their learning plans for the semester in the same way she was mapping out her teaching plan.

Once the group experience has been accomplished, an individual could certainly shift the chart into a spreadsheet and could move course components electronically. More sophisticated technology could also build on the basics as determined in the initial design. As we prepare for the next iteration of this workshop, we have identified an instructional technology consultant who will work with the participants on individual plans.

\section{Conclusion}

The Color-Coded Course Design Tool allowed faculty to graphically represent the various course activities across a semester, identify activities competing for student or faculty time, experiment as they rearranged components, and experience the energy of an active classroom as they interacted with each other to develop and polish their products. As faculty were led into a realm of design they may not have previously considered-the learner-centered design 
considerations-they were essentially forced to review their previous teachercentered design decisions. One participant wrote for our center's newsletter:

When I first learned of this workshop, the title appealed to me because I was looking for a way to restructure the design of some of my courses. So, when I signed up, I was focusing on the "Course Design" aspect, and regarding "Student Engagement" as a sort of subplot. However, the weeklong workshop demonstrated that without sufficient student engagement, even the most efficient course design is rather a waste of time. Student engagement both in and out of the classroom is now the core goal for all my classes, and the jumping-off point for my course design, rather than an after-thought (Carroll, 2002).

The exact building blocks and colors of the chart as explained here are not as important as faculty's growing recognition that effective course design is a complex puzzle, demanding attention to student engagement in the learning process.

\section{REFERENCES}

Alley, M. (1996). The craft of scientific writing. New York, NY: Springer-Verlag.

Anson, C. (2002). A WAC casebook: Scenes for faculty reflection and program development. New York, NY: Oxford University Press.

Baxter-Magolda, M. (1992). Knowing and reasoning in college. San Francisco, CA: Jossey-Bass.

Baxter-Magolda, M. (2001). Making their oun way: Narratives for transforming bigher education to promote self-development. Sterling. VA: Stylus.

Bean, J. (1996). Engaging ideas: The professor's guide to integrating writing, critical thinking and active learning in the classroom. San Francisco, CA: Jossey-Bass.

Campbell, W. E., \& Smith, K. A. (1997). New paradigms for college teaching. Edina, $\mathrm{MN}$ : Interaction.

Carroll, K. (2002, Fall). Faculty design courses to engage students-University Writing Program Annual Workshop. Virginia Tech Center for Excellence in Undergraduate Teaching Newsletter, 6.

Duffy, K., \& Jones, J. (1995). Teaching within the rhythms of the semester. San Francisco, CA: Jossey-Bass.

Grunert, J. (1997). The course syllabus: A learning-centered approach. Bolton, MA: Anker. 
Hjortshoj, K. (2001). The transition to college writing. Boston, MA: Bedford-St. Martin's.

Johnson, D. W., Johnson, R. T., \& Smith, K. A. (1998). Active learning: Cooperation in the college classroom. Edina, MN: Interaction.

Langer, J. A., \& Applebee, A. N. (1987). How writing shapes thinking. Urbana, IL: National Council of Teachers of English.

Sorcinelli, M. D., \& Elbow, P. (Eds.). (1997). Writing to learn: Strategies for assigning and responding to writing across the disciplines. New Directions for Teaching and Learning, No. 69. San Francisco, CA: Jossey-Bass.

Speck, B. W. (2000). Grading students' classroom writing: Issues and strategies (ASHE-ERIC Higher Education Report, 27[3]). Washington, DC: George Washington University, Graduate School of Education and Human Development.

Walvoord, B. E. (1986). Helping students write well: A guide for teachers in all disciplines. New York, NY: The Modern Language Association.

Walvoord, B. E., \& McCarthy, L. P. (1990). Thinking and writing in college: $A$ naturalistic study of students in four disciplines. Urbana, IL: National Council of Teachers of English.

\section{Contact:}

Marlene M. Preston

Coordinator, University Writing Program

Assistant Director, Center for Excellence in Undergraduate Teaching

105 Hillcrest

Virginia Tech

Blacksburg, VA 24060

Voice (540) 231-9832

Email mpreston@vt.edu

Marlene M. Preston is Coordinator of the University Writing Program at Virginia Tech. She also serves as Assistant Director of the Center for Excellence in Undergraduate Teaching and offers faculty devclopment workshops related to curriculum design and the development of student discourse. As a faculty member in the Department of Communication, she serves as Course Director for Communication Skills I and II, a freshman sequence that she designed to foster student writing and speaking skills. She helped to establish a campus speaking center for students, CommLab, and participates in the university's Learning Communities Initiative. 